\title{
Novel oral anticoagulants in primary care in patients with atrial fibrillation: a cross- sectional comparison before and after their introduction
}

Simon Schwill ${ }^{*}$, Katja Krug ${ }^{1}$, Frank Peters-Klimm¹, Jan van Lieshout ${ }^{2}$, Gunter Laux', Joachim Szecsenyi ${ }^{1}$ and Michel Wensing ${ }^{1}$

\begin{abstract}
Background: Novel oral anticoagulation (NOAC) has been introduced in recent years, but data on use in atrial fibrillation (AF) in primary care setting is scarce. In Germany, General Practitioners are free to choose type of oral anticoagulation $(\mathrm{OAC})$ in AF. Our aim was to explore changes in prescription-rates of OAC in German primary care before and after introduction of NOAC on the market.

Methods: Data of a representative morbidity registration project in primary care in Germany (CONTENT) were analysed. Patients with AF in 2011 or 2014 were included (before and after broad market authorization of NOAC, respectively). We defined three independent groups: patients from 2011 without follow-up (group A), patients from 2014 but without previous record in 2011 (group B) and patients with AF and records in 2011 and 2014 (group C).

Results: 2642 patients were included. Group A $(n=804)$ and $B(n=755)$ were comparable regarding patient characteristics. $87.3 \%$ of group $A$ and $84.8 \%$ of group $B$ had $\mathrm{CHA}_{2} \mathrm{DS}_{2}-\mathrm{VASc}-\mathrm{Score} \geq 2$, indicating a need for oral anticoagulation (OAC). Prescription of OAC increased from $23.1 \%(n=186)$ to $42.8 \%(n=323, p<.01)$ with stable use of vitamin-k-antagonist (22.6-24.9\%). NOAC increased from 0.6 to $19.2 \%(p<.01)$. Monotherapy with Acetylsalicylic acid (ASA) decreased from 15.3\% $(n=123)$ to $8.2 \%(n=62, p<.01)$. In group $C(n=1083)$, OAC increased from 35.3 to $55.4 \%(p<.01)$, with stable prescription rate of vitamin-k-antagonist (34.4-35.7\%). NOAC increased from 0.9 to 21. $5 \%(p<.01)$.

Conclusions: In summary, our study showed a significant increase of OAC over time, which is fostered by the use of NOAC but with a stable rate of VKA and a sharp decrease of ASA. Patients on VKA are rarely switched to NOAC, but new patients with AF are more likely to receive NOAC.
\end{abstract}

Keywords: Atrial fibrillation, Stroke prevention, Oral anticoagulation, Vitamin K antagonists, Novel oral anticoagulants

\footnotetext{
* Correspondence: simon.schwill@med.uni-heidelberg.de

${ }^{1}$ Department of General Practice and Health Services Research, University

Hospital Heidelberg, Heidelberg, Germany

Full list of author information is available at the end of the article
}

(c) The Author(s). 2018 Open Access This article is distributed under the terms of the Creative Commons Attribution 4.0 International License (http://creativecommons.org/licenses/by/4.0/), which permits unrestricted use, distribution, and reproduction in any medium, provided you give appropriate credit to the original author(s) and the source, provide a link to the Creative Commons license, and indicate if changes were made. The Creative Commons Public Domain Dedication waiver (http://creativecommons.org/publicdomain/zero/1.0/) applies to the data made available in this article, unless otherwise stated. 


\section{Background}

Atrial fibrillation (AF) is the most common cardiac arrhythmia, with an estimated prevalence of 1.5 to $2 \%$ of the general population, which is increasing worldwide, driven by an ageing population [1-3]. Nearly $10 \%$ of people above 75 years suffer from AF [4]. Patients have an almost fivefold higher risk of stroke [5] and mortality is up to 2.5 times higher compared with age-matched individuals [2].

Regardless of causal treatment, prophylaxis of stroke by use of oral anticoagulation (OAC) was shown to reduce risk of stroke and therefore is recommend in patients with AF by international guidelines $[6,7]$. The $\mathrm{CHA}_{2} \mathrm{DS}_{2^{--}}$ VASc-Score has been recommended for risk stratification [6-8]. For decades vitamin-K antagonists (VKA) had been the only $\mathrm{OAC}$ in $\mathrm{AF}$, accompanied by prescription of acetylsalicylic acid (ASA), which is no longer recommended [6,7]. In recent years novel-oral-anticoagulants (NOAC) such as Apixaban, Dabigatran, Edoxaban and Rivaroxaban offered an alternative OAC to prevent stroke in non-valvular AF. Use of NOAC is increasing and recently updated guidelines on AF by the European Society of Cardiology advocate use of NOAC over VKA [6]. Clinical guidelines on AF for primary care physicians present NOAC as a valid option, but do not necessarily recommend changing patients from VKA to NOAC [9].Data on use of (N)OAC in AF in routine primary care setting is scarce [10-14]. In Germany, NOAC were licensed for the indication of oral anticoagulation for the prevention of stroke in non-valvular atrial fibrillation between November 2011 and June 2015: Dabigatran in 11 /2011, Rivaroxaban in 12/2011, Apixaban in 12/2012 and Edoxaban in $06 / 2015$ [15-18]. The aims of this study were to document changes in prescription-rates of OAC (VKA and $\mathrm{NOAC}$ ) in primary care patients with AF in Germany before and after introduction of NOAC on the market, and to explore whether known patients with AF were switched onto NOAC.

\section{Methods \\ Study design}

We performed a retrospective epidemiological study in primary care practices including a cross-sectional comparison of two independent samples and a cross-sectional comparison of same patients at two points of time.

\section{Setting}

Data were derived from the CONTinuous-morbidityregistration-Epidemiologic-NeTwork (CONTENT) in South-Germany, which started in 2005 [19]. A total of 43 general practices were involved in this study. CONTENT provides representative data in terms of social, ethnic and economic backgrounds as well as urban, suburban and rural areas. The quality of data is high due to constant education of participating teams as well as continuous feedback on recording quality to participating physicians.

\section{Sample}

In 2016, data of CONTENT starting in 2005 up to 31.12.2014 was included in the study and analysed retrospectively. We performed a before and after comparison on the prescription of OAC, which compared data from 2011, when there was little experience with NOAC and data from 2014, when Apixaban, Dabigatran and Rivaroxaban were broadly available. Edoxaban was not licensed in Germany in 2014. Out of all patients with diagnosed AF (ICD I48.0) we included patients with AF from 01.01.2011-31.12.2011 or 01.01.2014-31.12.2014. Afterwards, we, defined three independent groups: patients with AF in 2011 but without follow-up in 2014(group A), patients with AF in 2014 but without previous record in 2011 (group B) and patients with AF and records in 2011 and 2014 (group C). Difference between groups $\mathrm{A}$ and $\mathrm{B}$ was related to newly diagnosed AF, mortality and patient change of practice. Patients of group $\mathrm{C}$ were not included in other groups neither $\mathrm{A}$ nor B.

\section{Measures}

Relevant data were extracted from the CONTENT database. For each patient age, gender as well as prescription of medication, diagnoses and specialist referrals were determined. Age was calculated from the year of birth. Gender and age were used for measurement of $\mathrm{CHA}_{2} \mathrm{DS}_{2}$-VASc-Score. Diagnoses were given as ICD-10 codes. Prescriptions were given as ATC-codes (Anatomical Therapeutical Classification for medication, World Health Organization). Secondly, prescriptions were analysed for VKA [Phenprocoumon = ATC-B01AA04] and NOAC $[$ Apixaban $=$ ATC-B01AX08, Dabigatran = ATC-B01AE07, Rivaroxaban $=$ ATC-B01AX06] and ASA [acetylsalicylic-acid $=$ ATC-B01AC06]. We extracted diagnoses needed for the $\mathrm{CHA}_{2} \mathrm{DS}_{2}$-VASc-Score: Congestive heart failure (I50*), Hypertension (I10.*) Diabetes (E10.-E11.*, E14.*), Stroke (I63.*) and Vascular disease (I70.*). At time of study $\mathrm{CHA}_{2} \mathrm{DS}_{2}$-VASc-Score $\geq 2$ indicated OAC in patients with $\mathrm{AF}^{7}$. If data of hypertension or diabetes were not encoded, prescription of an antidiabetic [ATC-A10] or antihypertensive [angiotensin-converting-enzyme-inhibitor = ATC-C09AA, Angiotensin-II-receptor-antagonists = ATC-C09CA, Nifedipine = ATC-C08CA05, Hydrochlorothiazide $=$ ATC-C03AA03 $]$ medication was accepted instead.

To address potential contraindications we extracted diagnoses renal insufficiency (N17.*-N19.*), coagulopathy (D68.-D69.*), intracranial bleeding (I60.-I62.*, S06.4-S06.6.", S06.9), epistaxis (R04.0-R04.2), gastrointestinal bleeding 
(K92.0-K92.2, K62.5) and stroke (I63.-I64.*). We recorded specialist referrals only to cardiologists.

\section{Data analysis}

Patient-characteristics were summarized in terms of frequencies of categories, means with standard deviation and medians with interquartile range for continuous variables. Differences between independent groups A and B were tested in Chi-squared-tests for frequencies, Fishers exact test, t-tests for independent samples or MannWhitneyU-tests for continuous data, dependent on data distribution. Changes over time (group C) were analysed with McNemar's-tests for frequencies and t-tests for dependent samples or Wilcoxon-signed-rank-tests for continuous data, dependent on data distribution. $P$-values $<0.05$ were considered to indicate statistical significance. Due to the exploratory character of the analysis, there was no correction for multiple testing. All analyses were performed with IBM SPSS version 21.0.

\section{Results}

\section{Patient characteristics}

Total number of patient in CONTENT in 2011 was $n=$ 145,461 (point-prevalence of AF on 31.12.2011: 1.51\%), in $2014 n=207,253$ (point-prevalence of AF on 31.12.2014: $1.85 \%$ ).In total, data of $n=2642$ patients from 43 general practices was obtained in this study. We included $n=804$ in Group A, $n=755$ in Group B and $n$ $=1083$ in Group C. In two-sample comparison, presented in Table 1, groups A and B did not differ regarding sex or comorbidities, but group B was younger than group A $(p<0.01)$. Number of patients $>75$ years, contributing to $\mathrm{CHA}_{2} \mathrm{DS}_{2}$-VASc-Score twice, was $66.3 \%$ in group A $(n=533)$ which was comparable to $61.9 \%$ in group B $(n=467) .87 .3 \%$ of patients in group A $(n=702)$ and $84.8 \%$ of patients in group $\mathrm{B}(n=640)$ presented with $\mathrm{CHA}_{2} \mathrm{DS}_{2}$-VASc-Score $\geq 2$, which indicated OAC at time of the study $(\mathrm{p}=\mathrm{n} . \mathrm{s}$.).

Group C included $\mathrm{n}=1083$ patients (Table 2), of whom $51.9 \%$ were above 75 years in $2011(n=562)$ and $64.4 \%$ in $2014(n=697)$. Percentage of patients with $\mathrm{CHA}_{2} \mathrm{DS}_{2--}$ VASc-Score $\geq 2$ increased from $81.6 \%(n=884)$ to $83.8 \%$ $(n=908, p<.01) .91 \%$ of patients with diagnosed AF presented with at least one additional diagnosis, such as renal insufficiency $(n=1003)$.

\section{Prescription of oral-anticoagulation}

Two-sample comparison revealed an increase of prescription of OAC from $23.1 \%$ in $2011(n=186)$ to $42.8 \%$ in $2014(n=323, p<.01)$. Prescription-rate of VKA remained stable $(22.6 \%, n=182$ and $24.9 \%, n=188)$. Prescription of NOAC increased from $0.6 \%(\mathrm{n}=5)$ to $19.2 \%$ $(n=145, p<.01)$, whereas monotherapy with ASA decreased from $15.3 \%(n=123)$ to $8.2 \%(n=62, p<.01)$.
The majority of patients with NOAC in 2014 received Rivaroxaban $(84.8 \%, n=121)$ compared to Dabigatran $(9.6 \%, \mathrm{n}=14)$ and Apixaban $(6.9 \%, \mathrm{n}=10)$. In 2014, cardiologists were involved more often compared with 2011 (15.5\%, $n=125$ versus $21.9 \%, n=165, p<.01)$.

In group C (involving longitudinal comparison, $n=1083$ ), prescription of OAC increased from $35.3 \%(n=382)$ to $55.4 \%(n=600, \mathrm{p}<.01)$ with similar prescription rate of VKA $(34.4 \%, n=373$ and $35.7 \%, n=387)$. Mean annual prescriptions per patient increased from 19.3 to 22.4 (p $<.01)$. Prescription of NOAC in group $\mathrm{C}$ increased from 0.9 to $21.5 \%(\mathrm{p}<.01)$. Prescription of ASA decreased over time $(2011: 12.6 \%, n=136,2014: 9.0 \%, n=97, \mathrm{p}<.01) .11 .9 \%$ $(n=44)$ of patients with VKA were switched to NOAC and in $19.9 \%$ OAC $(n=74)$ was discontinued completely. In 2011, 9 patients received a NOAC, of which 4 were stopped until 2014 and one patient was switched to VKA. $11.9 \%(n=44)$ of patients with VKA were switched to NOAC. In 2014, majority of patients with AF and OAC received VKA: Group B: $56 \% n=188 / 333$, Group C: $62.5 \% n=387 / 619$.

In group C, $22.6-24.2 \%$ of patients attended a cardiologist but involvement of cardiologists did not significantly change over time (2011: 22.6\%, 2014: $24.2 \%, p<.32$ ). If cardiologists were involved, prescription of OAC increased over time from $51.6 \%$ in 2011 to $67.2 \%$ of patients in $2014(p<.01)$.

\section{Discussion}

In patients with recorded AF in German primary care there was in increase in prescription-rate for OAC between 2011 and 2014: A cross-sectional comparison revealed that in $201442.8 \%(n=323)$ of patients with AF received OAC compared to $23.1 \%(n=186)$ in 2011 . A longitudinal comparison (group $C$ ) showed an increase of OAC in AF from $35.3 \%(n=383)$ to $55.4 \%(n=600)$. This increase in prescription-rate was mainly due to new prescription of NOAC, while prescription-rate of VKA remained stable. In longitudinal comparison (group C) use of NOAC increased to $21.4 \%(n=232)$ of patients with AF in 2014, with Rivaroxaban as most frequently prescribed. In 2014, cardiologists were involved in about $25 \%$ of patients (Group B: $21.9 \%(n=165)$ and Group C: $24.2 \%(n=262)$ and their involvement increased the likelihood of OAC prescribing. However, analysis showed no difference in cardiologists preference between VKA and NOAC and in 2014 majority of patients with OAC in AF still received VKA (Group B: $56 \% n=188 / 333$, Group C: $62.5 \% n=387 / 619)$. Our analysis showed that patients were rarely switched from VKA to NOAC but were more likely to receive NOAC if diagnosed newly.

Interestingly, over $80 \%$ of patients with $\mathrm{AF}$ (group A 87.3\%, group B $84.8 \%$, group C $81.6 \% / 83.8 \%$ ) presented with CHADS-VasC Score $\geq 2$ indicating OAC (at time of 
Table 1 Patient characteristics comparing 2011 and 2014 independently

\begin{tabular}{|c|c|c|c|c|c|}
\hline & & & GROUP A (2011) & GROUP B (2014) & $p$-value \\
\hline \multirow[t]{32}{*}{ patients (n) } & total & & 804 & 755 & \\
\hline & \multirow[t]{3}{*}{ gender (\%) } & male & $374(46.5 \%)$ & $388(51.4 \%)$ & $.06^{\mathrm{a}}$ \\
\hline & & female & $429(53.4 \%)$ & $367(48.6 \%)$ & \\
\hline & & undetermined & $1(0.1 \%)$ & 0 & \\
\hline & \multirow[t]{5}{*}{ age (years) } & Median (IQR) & $79(71-86)$ & $77(70-83)$ & $<.01^{\mathrm{b}}$ \\
\hline & & Min - Max & 19-99 & $18-103$ & \\
\hline & & $<65$ & $92(11.4 \%)$ & $118(15.6 \%)$ & \\
\hline & & $65-74$ & $179(22.3 \%)$ & $170(22.5 \%)$ & \\
\hline & & $\geq 75$ & $533(66.3 \%)$ & $467(61.9 \%)$ & \\
\hline & \multirow[t]{7}{*}{ additional diagnosis } & at least 1 additional & $750(93.3 \%)$ & $724(95.9 \%)$ & $.02^{\mathrm{a}}$ \\
\hline & & renal insufficiency & $54(6.7 \%)$ & $55(7.3 \%)$ & $.66^{\mathrm{a}}$ \\
\hline & & coagulopathy & $13(1.6 \%)$ & $17(2.3 \%)$ & $.36^{\mathrm{a}}$ \\
\hline & & intracranial bleeding & $8(1.0 \%)$ & $6(0.8 \%)$ & $.68^{\mathrm{a}}$ \\
\hline & & epistaxis & $7(0.9 \%)$ & $10(1.3 \%)$ & $.39^{\mathrm{a}}$ \\
\hline & & gastrointestinal bleeding & $15(1.9 \%)$ & $12(1.6 \%)$ & $.68^{\mathrm{a}}$ \\
\hline & & stroke & $43(5.3 \%)$ & $34(4.5 \%)$ & $.44^{\mathrm{a}}$ \\
\hline & \multirow[t]{3}{*}{$\mathrm{CHA}_{2} \mathrm{DS}_{2}$-VASC: } & 0 & $48(6.0 \%)$ & $56(7.4 \%)$ & $.34^{\mathrm{a}}$ \\
\hline & & 1 & $54(6.7 \%)$ & $59(7.8 \%)$ & \\
\hline & & $\geq 2$ & $702(87.3 \%)$ & $640(84.8 \%)$ & \\
\hline & \multirow[t]{6}{*}{ prescriptions (per year) } & patients with at least 1 prescription & $684(85.1 \%)$ & $677(89.7 \%)$ & $<.01^{\mathrm{a}}$ \\
\hline & & $\mathrm{Md}(\mathrm{IQR})$ & $12(5-25)$ & $15(6-24)$ & $.31^{\mathrm{b}}$ \\
\hline & & Min - Max & $1-123$ & $1-123$ & \\
\hline & & all patients & & & $.02^{\mathrm{b}}$ \\
\hline & & $\mathrm{Md}(\mathrm{IQR})$ & $10(2-22.8)$ & $13(3-23)$ & \\
\hline & & Min - Max & $0-123$ & $0-123$ & \\
\hline & \multirow[t]{5}{*}{ OAC } & VKA or NOAC & $186(23.1 \%)$ & $323(42.8 \%)$ & $<.01^{\mathrm{a}}$ \\
\hline & & VKA & $182(22.6 \%)$ & $188(24.9 \%)$ & $.29^{\mathrm{a}}$ \\
\hline & & Rivaroxaban & $0(0.0 \%)$ & $121(16.0 \%)$ & $<.01^{\mathrm{a}}$ \\
\hline & & Dabigatran & $5(0.6 \%)$ & $14(1.9 \%)$ & $.03^{\mathrm{a}}$ \\
\hline & & Apixaban & $0(0.0 \%)$ & $10(1.3 \%)$ & $<.01^{\mathrm{c}}$ \\
\hline & \multicolumn{2}{|c|}{ ASA (without additional OAC) ${ }^{d}$} & $123(15.3 \%)$ & $62(8.2 \%)$ & $<.01^{\mathrm{a}}$ \\
\hline & \multicolumn{2}{|c|}{ consultation of cardiologist } & $125(15.5 \%)$ & 165 (21.9\%) & $<.01^{\mathrm{a}}$ \\
\hline
\end{tabular}

CONTENT-Patients with diagnosis of atrial fibrillation, which were registered only once, either in 2011 (group A) or in 2014 (group B). OAC oral anticoagulation, VKA vitamin-k antagonists, NOAC novel oral anticoagulation, ASA Acetylsalicylic acid ${ }^{\mathrm{a}}$ Chi ${ }^{2}$-test, ${ }^{\mathrm{b}}$ Mann-Whitney-U-test, ${ }^{\mathrm{c}}$ Fisher's exact test

dIndication for ASA (100 mg), such as peripheral vascular disease or post-stroke or post-myocardial infarction or else and either as primary or secondary prophylaxis, could not clearly be stated

study). High percentage might be explained by the age, as in our study about two third of patients were 75 years of age or higher, scoring 2 within the $\mathrm{CHA}_{2} \mathrm{DS}_{2}$-VASc-Score, and thereby had a formal indication for OAC at time of the study. However, this represents the population in primary care.Recently updated guidelines on AF postulate evidence that OAC can prevent majority of ischemic strokes in AF and prolong life [6]. Although our findings suggest suboptimal prescribing-rates of $\mathrm{OAC}$, they should be interpreted carefully. Patient populations in clinical trials of OAC differ regarding age, sex and co-morbidities from those treated in primary care $[20,21]$.

The benefit-risk-ratio of OAC and NOAC more particularly, may be less positive in primary care patients compared to patients in cardiology trials. In routine data, we miss documentation of reasons for not-prescribing OAC such as increased bleeding risk, alcohol-abuse, liver-failure or uncontrolled hypertension (which could not be accessed). Qualitative studies on prescribing OAC in 
Table 2 Patient characteristics over time

\begin{tabular}{|c|c|c|c|c|c|}
\hline \multirow{2}{*}{ patients (n) } & & & GROUP C (2011) & GROUP C (2014) & $p$-value \\
\hline & \multicolumn{2}{|l|}{ total } & \multicolumn{2}{|l|}{1083} & $n / a$ \\
\hline & gender (\%) & male & \multicolumn{2}{|l|}{$584(53.9 \%)$} & $\mathrm{n} / \mathrm{a}$ \\
\hline & & female & \multicolumn{2}{|l|}{$470(43.4 \%)$} & \\
\hline & & undetermined & \multicolumn{2}{|l|}{$29(2.7 \%)$} & \\
\hline & \multirow[t]{5}{*}{ age (years) } & Median (IQR) & $75(68-81)$ & $78(71-84)$ & $\mathrm{n} / \mathrm{a}$ \\
\hline & & Min - Max & 24-93 & $27-96$ & \\
\hline & & $<65$ & $200(18.5 \%)$ & $145(13.4 \%)$ & \\
\hline & & $65-74$ & $321(29.6 \%)$ & $241(22.3 \%)$ & \\
\hline & & $\geq 75$ & $562(51.9 \%)$ & $697(64.4 \%)$ & \\
\hline & \multirow[t]{7}{*}{ additional diagnosis } & patients With at least 1 & $1003(92.6 \%)$ & 986 (91.0\%) & $.13^{\mathrm{a}}$ \\
\hline & & renal insufficiency & $61(5.6 \%)$ & $65(6.0 \%)$ & $.77^{\mathrm{a}}$ \\
\hline & & coagulopathy & $17(1.6 \%)$ & $17(1.6 \%)$ & $1.0^{\mathrm{a}}$ \\
\hline & & intracranial bleeding & $4(0.4 \%)$ & $5(0.5 \%)$ & $1.0^{\mathrm{a}}$ \\
\hline & & epistaxis & $21(1.9 \%)$ & $14(1.3 \%)$ & $.30^{\mathrm{a}}$ \\
\hline & & gastrointestinal bleeding & $13(1.2 \%)$ & $17(1.6 \%)$ & $.59^{\mathrm{a}}$ \\
\hline & & stroke & $33(3.0 \%)$ & $28(2.6 \%)$ & $.58^{\mathrm{a}}$ \\
\hline & \multirow[t]{4}{*}{$\mathrm{CHA}_{2} \mathrm{DS}_{2}-\mathrm{VASC}:$} & 0 & $92(8.5 \%)$ & $59(5.4 \%)$ & $<.01^{\mathrm{a}}$ \\
\hline & & 1 & $100(9.2 \%)$ & $87(8.0 \%)$ & \\
\hline & & $\geq 2$ & $884(81.6)$ & $908(83.8 \%)$ & \\
\hline & & not computable & $7(0.6 \%)$ & $29(2.7 \%)$ & $n / a$ \\
\hline & \multirow[t]{6}{*}{ prescriptions (per year) } & total & $1056(97.5 \%)$ & 1064 (98.2\%) & $n / a$ \\
\hline & & M (SD) & $19.4(14.6)$ & $22.6(16.5)$ & $<.01^{\mathrm{b}}$ \\
\hline & & Min - Max & $1-118$ & $1-115$ & \\
\hline & & all patients including those without prescription & & & $<.01^{\mathrm{b}}$ \\
\hline & & $M(S D)$ & $18.8(14.8)$ & $22.0(16.7)$ & \\
\hline & & Min - Max & $0-118$ & $0-115$ & \\
\hline & \multirow[t]{5}{*}{$O A C^{1}$} & VKA or NOAC & $382(35.3 \%)$ & $600(55.4 \%)$ & $<.01^{\mathrm{a}}$ \\
\hline & & VKA & $373(34.4 \%)$ & $387(35.7 \%)$ & $.41^{\mathrm{a}}$ \\
\hline & & Rivaroxaban & $3(0.3 \%)$ & $181(16.7 \%)$ & $<.01^{\mathrm{a}}$ \\
\hline & & Dabigatran & $7(0.6 \%)$ & $23(2.1 \%)$ & $<.01^{\mathrm{a}}$ \\
\hline & & Apixaban & none & $28(2.6 \%)$ & $\mathrm{n} / \mathrm{c}$ \\
\hline & \multicolumn{2}{|c|}{ ASA (without additional OAC) $)^{2}$} & $136(12.6 \%)$ & $97(9.0 \%)$ & $<.01^{\mathrm{a}}$ \\
\hline & \multicolumn{2}{|c|}{ consultation of cardiologist } & $245(22.6 \%)$ & $262(24.2 \%)$ & $.32^{\mathrm{a}}$ \\
\hline
\end{tabular}

CONTENT-Patients with diagnosis of atrial fibrillation, which were observed over time including data from 2011 and follow-up in 2014 (group C). OAC = oral anticoagulation, VKA = vitamin-k antagonists, NOAC = novel oral anticoagulation, ASA = Acetylsalicylic acid

${ }^{1}$ Different prescriptions per year such as VKA and NOAC or NOAC and NOAC was possible $(n=29)$

${ }^{2}$ Indication for ASA (100 mg), such as peripheral vascular disease or post-stroke or post-myocardial infarction or else and either as primary or secondary prophylaxis, could not clearly be stated

${ }^{\mathrm{a}}$ McNemar test, ${ }^{\mathrm{b}}$ t-test for dependent samples

primary care are rare, but it can be assumed that low life expectancy, high risk of falling and bleeding, as well as frailty are reasons to refrain from prescribing OAC in AF. This contrasts with views of experts, such as the European-Primary-Care-Cardiovascular-Society (EPCCS), who claim that a high bleeding-risk-score (such as HAS-BLED, ORBIT or ABC) should generally not result in withholding $\mathrm{OAC}[6,22]$.
Our data showed a significant increase in the prescription-rate of $\mathrm{OAC}$ in $\mathrm{AF}$ before and after market-share of NOAC. The design of our study does not allow causal attribution so it is not known if this increase might be caused by an alternative medication to VKA general practitioners had awaited, by an update and implementation of guidelines on non-valvular AF, by a generous promotion of NOAC or a mix of it all. 
We showed majority of patients with $\mathrm{AF}$ and $\mathrm{OAC}$ in 2014 received VKA. Until today, whether NOAC or VKA are safer and/or more effective in prophylaxis of stroke in non-valvular AF remains a key-point of experts-discussions as well as on-going trials [23]. In summary, there is a need for further research into the determinants of prescribing $\mathrm{OAC}$ in patients with $\mathrm{AF}$ in primary care.

\section{Strengths and limitations}

Strengths of this study are large number of primary care practices and reasonably high quality of patient records. Participating practices had university affiliation, which is associated with higher involvement in continuous medical education. It may be noted that in the German health care system documentation of AF (ICD48.*) must be confirmed by Electrocardiogram (ECG), as recommend in updated guidelines on AF [6]. All participating practices were well experienced in daily use of ECG, but we could not independently verify the recorded diagnosis of AF. Secondly, due to routine data out of patient charts underreporting of AF (ICD48.*) as well as comorbidities and follow-up might be possible [24]. However, we focussed on the prescriptions of $\mathrm{OAC}$ for patients with $\mathrm{AF}$ and those with undocumented AF cannot be considered for treatment. Finally, we did not know which patients did not receive anticoagulants due to (relative or absolute) contraindications such as liver dysfunction.

\section{Conclusions}

We aimed to document prescription-rates of OAC (VKA and NOAC) in primary care patients with AF in Germany before and after broad market-share of NOAC and to explore whether known patients with AF were switched onto NOAC. In summary, our study showed a significant increase of OAC over time, which is fosterer by the use of NOAC but with a stable rate of VKA and a sharp decrease of ASA. Patients on VKA are rarely switched to NOAC, but new patients with AF are more likely to receive NOAC. In 2014, $45 \%$ of patients with CHA2DS2-VASc-Score $\geq 2$ were not prescribed OAC, suggesting room for improvement. Further research is needed to identify factors contributing to this.

\section{Abbreviations}

AF: Atrial fibrillation; ASA: Acetylsalicylic acid; CHA2DS2-VASc: Congestive heart failure, Hypertension, Age, Diabetes, Stroke, Vascular Disease, Age, Sex category; CONTENT: CONTinuous-morbidity-registration-EpidemiologicNeTwork; ECG: Electrocardiogram; ICD: International Statistical Classification of Diseases and Related Health Problems; NOAC: Novel oral anticoagulation; OAC: Oral anticoagulation; VKA: Vitamin-K antagonists

\section{Acknowledgements}

We want to thank the participating practices for providing high quality of data.
Availability of data and materials

The datasets used and/or analysed during the current study are available from the corresponding author on reasonable request.

\section{Authors' contributions}

SS contributed to conception and design of the study, to acquisition, analysis and interpretation of data and to drafting and revising the manuscript. KK contributed to design of the study, to acquisition, analysis and interpretation of data and to drafting and revising the manuscript. FP-K contributed to analysis and interpretation of data and critically revised the manuscript. JVL contributed to analysis and interpretation of data and critically revised the manuscript. GL contributed to conception and design of the study, to acquisition and analysis of data and critically revised the manuscript. JS contributed to conception and design of the study, to interpretation of data and critically revised the manuscript. MW contributed to conception and design of the study, to analysis and interpretation of data and to drafting and revising the manuscript. All authors read and approved the final manuscript.

\section{Ethics approval and consent to participate}

Study was approved by the ethics committee of the University of Heidelberg (DIN EN ISO 9001, approval number 442/2005). No need for consent was granted because of the use of pseudonymous data.

\section{Consent for publication}

Not applicable.

\section{Competing interests}

The authors declare that they have no competing interests.

\section{Publisher's Note}

Springer Nature remains neutral with regard to jurisdictional claims in published maps and institutional affiliations.

\section{Author details}

${ }^{1}$ Department of General Practice and Health Services Research, University Hospital Heidelberg, Heidelberg, Germany. ${ }^{2}$ Radboud Institute of Health Sciences, Radboud University Medical Centre, Nijmegen, Netherlands.

Received: 12 November 2017 Accepted: 13 June 2018

Published online: 18 July 2018

\section{References}

1. Piccini JP, Hammill BG, Sinner MF, Jensen PN, Hernandez AF, Heckbert SR, et al. Incidence and prevalence of atrial fibrillation and associated mortality among Medicare beneficiaries, 1993-2007. Circ Cardiovasc Qual Outcomes. 2012;5:85-93.

2. Schnabel RB, Yin X, Gona P, Larson MG, Beiser AS, McManus DD, et al. 50 year trends in atrial fibrillation prevalence, incidence, risk factors, and mortality in the Framingham heart study: a cohort study. Lancet. 2015;386: 154-62.

3. Chugh SS, Havmoeller R, Narayanan K, Singh D, Rienstra M, Benjamin EJ, et al. Worldwide epidemiology of atrial fibrillation: a global burden of disease 2010 study. Circulation. 2014;129:837-47.

4. Heeringa J, van der Kuip DA, Hofman A, Kors JA, van Herpen G, Stricker BH, et al. Prevalence, incidence and lifetime risk of atrial fibrillation: the Rotterdam study. Eur Heart J. 2006;27:949-53.

5. Wolf PA, Abbott RD, Kannel WB. Atrial fibrillation as an independent risk factor for stroke: the Framingham study. Stroke. 1991;22:983-8.

6. Kirchhof P, Benussi S, Kotecha D, Ahlsson A, Atar D, Casadei B, et al. 2016 ESC guidelines for the management of atrial fibrillation developed in collaboration with EACTS: the task force for the management of atrial fibrillation of the European Society of Cardiology (ESC)developed with the special contribution of the European heart rhythm association (EHRA) of the ESCEndorsed by the European stroke organisation (ESO). Eur Heart J. 2016; 37(38):2893-962. PMID: 27567408.

7. January CT, Wann LS, Alpert JS, Calkins H, Cigarroa JE, Cleveland JC Jr, et al. 2014 AHA/ACC/HRS guideline for the management of patients with atrial fibrillation: a report of the American College of Cardiology/American Heart Association task force on practice guidelines and the Heart Rhythm Society. Circulation. 2014;130:e199-267. 
8. Lip GY, Nieuwlaat R, Pisters R, Lane DA, Crijns HJ. Refining clinical risk stratification for predicting stroke and thromboembolism in atrial fibrillation using a novel risk factor-based approach: the euro heart survey on atrial fibrillation. Chest. 2010;137:263-72.

9. Deutsche Gesellschaft fürAllgemeinmedizin und Familienmedizin. New oral anticoagulants, AWMF-Reg. 053/031. 2013, updated 2017 http://www.awmf. org/fileadmin/user_upload/Leitlinien/053_D_Ges_fuer_Allgemeinmedizin_ und_Familienmedizin/053-031 ke_S1_Antikoagulantien_NOAK_2017-01.pdf. Accessed June 5th 2018.

10. Mueller S, Pfannkuche M, Breithardt G, Bauersachs R, Maywald U, Kohlmann $T$, et al. The quality of oral anticoagulation in general practice in patients with atrial fibrillation. Eur J Intern Med. 2014;25:247-54.

11. Ulrich LR, Mergenthal K, Petersen JJ, Roehl I, Rauck S, Kemperdick B, et al. Anticoagulant treatment in German family practices - screening results from a cluster randomized controlled trial. BMC Fam Pract. 2014:15:170.

12. Beyer-Westendorf J, Ehlken B, Evers T. Real-world persistence and adherence to oral anticoagulation for stroke risk reduction in patients with atrial fibrillation. Europace. 2016;18:1150-7.

13. Haeusler KG, Gerth A, Limbourg T, Tebbe U, Oeff M, Wegscheider K, et al. Use of vitamin $\mathrm{K}$ antagonists for secondary stroke prevention depends on the treating healthcare provider in Germany - results from the German AFNET registry. BMC Neurol. 2015;15:129.

14. Robson J, Dostal I, Mathur R, Sohanpal R, Hull S, Antoniou S, et al. Improving anticoagulation in atrial fibrillation: observational study in three primary care trusts. Br J Gen Pract. 2014;64:e275-81.

15. Drug Commission of the Germal Medical Association. https://www. akdae.de/Arzneimitteltherapie/NA/Archiv/201303-Eliquis.pdf. Accessed June 5th 2018.

16. Drug Commission of the Germal Medical Association. https://www akdae.de/Arzneimitteltherapie/NA/Archiv/2011030-Pradaxa.pdf. Accessed June 5th 2018.

17. Drug Commission of the Germal Medical Association. https://www. akdae.de/Arzneimitteltherapie/NA/Archiv/201310-Xarelto.pdf. Accessed June 5th 2018.

18. Drug Commission of the Germal Medical Association. https://www.akdae. de/Arzneimitteltherapie/NA/Archiv/201504-Lixiana-DVT.pdf. Accessed June 5th 2018.

19. Laux G, Koerner T, Rosemann T, Beyer M, Gilbert K, Szecsenyi J. The CONTENT project: a problem-oriented, episode-based electronic patient record in primary care. Informatics in primary care. 2005;13:249-55.

20. Andreotti F, Rocca B, Husted S, Aijan RA, ten Berg J, Cattaneo M, et al. Antithrombotic therapy in the elderly: expert position paper of the European Society of Cardiology Working Group on thrombosis. Eur Heart J. 2015:36:3238-49.

21. Halperin JL, Hankey GJ, Wojdyla DM, Piccini JP, Lokhnygina Y, Patel MR, et al. Efficacy and safety of rivaroxaban compared with warfarin among elderly patients with nonvalvular atrial fibrillation in the rivaroxaban once daily, oral, direct factor $\mathrm{Xa}$ inhibition compared with vitamin $\mathrm{K}$ antagonism for prevention of stroke and embolism trial in atrial fibrillation (ROCKET AF). Circulation. 2014;130:138-46.

22. Hobbs FR, Taylor CJ, Jan Geersing G, Rutten FH, Brouwer JR. European primary care cardiovascular society Swg. European primary care cardiovascular society (EPCCS) consensus guidance on stroke prevention in atrial fibrillation (SPAF) in primary care. Eur J Prev Cardiol. 2016;23:460-73.

23. Ruff CT, Giugliano RP, Braunwald E, Hoffman EB, Deenadayalu N, Ezekowitz $M D$, et al. Comparison of the efficacy and safety of new oral anticoagulants with warfarin in patients with atrial fibrillation: a meta-analysis of randomised trials. Lancet. 2014;383:955-62.

24. Last JM, Adelaide MB. The iceberg "completing the clinical picture" in general practice. Lancet. 1963;282:28-31.

Ready to submit your research? Choose BMC and benefit from:

- fast, convenient online submission

- thorough peer review by experienced researchers in your field

- rapid publication on acceptance

- support for research data, including large and complex data types

- gold Open Access which fosters wider collaboration and increased citations

- maximum visibility for your research: over $100 \mathrm{M}$ website views per year

At BMC, research is always in progress.

Learn more biomedcentral.com/submissions 